\title{
ABC Algorithm Based System Modelling for Tuning the Fractional Order PID Controllers
}

\author{
Halit Senberber, Aytekin Bagis \\ Department of Electrical and Electronics Engineering, \\ Faculty of Engineering, Erciyes University, \\ 38039 Kayseri, Turkey \\ halitsenberber@erciyes.edu.tr
}

\begin{abstract}
The effectiveness of the model structure for designing control system is highly depending on the right selection of tuning parameters belonging of the algorithms. No doubt, preferable parameter estimation leads to better results for the modelling process. This study consists of two main parts. In the first part, fractional and integer model structures with time delay are proposed for integer-order systems using artificial bee colony (ABC) algorithm and differential evolution (DE) algorithm. The second part of the study is the fractional order PID controller design based on the use of new models obtained with the help of Matlab/Simulink software package. While the integrated square error (ISE) is preferred in the modelling process as the performance criterion, four different performance indices are chosen as ISE, integral time-square error (ITSE), integral absolute error (IAE) and integral timeweighted absolute error (ITAE) during the controller design phase. It is shown that, the results obtained with fractional modelling have achieved better results than the integer order modelling. Furthermore, the controller designs for the algorithm based models proposed in the first stage of the study present a satisfactory performance.
\end{abstract}

Index Terms-Artificial bee colony algorithm; Fractional order PID; Fractional order system modelling; Fractional system design.

\section{INTRODUCTION}

Learning of internal structure that characterizes the system by using experimental or mathematical data is called as system modelling [1]-[4]. The main purpose of the system modelling is to reflect the characteristics of the system using lower order process in general. One of the effective methods of the linear and nonlinear system identification is to use the adaptive algorithms or artificial intelligence techniques.

In the literature, it has been involved in a lot of work related to modelling in recent years [1]-[10]. Mete et al. [5] presented system modelling based on cascade of a nonlinear second order volterra (SOV) model and a linear FIR model using DE algorithms. Another study which is examination of ABC algorithm performance in the modelling of higher order systems is presented by Bagis and Senberber [4]. In the study of Deng, a system modelling approach based on PSO algorithm is reported [6]. Chaudhary and Raja [7] developed a type of fractional order the LMS (least mean square) algorithm for system identification of Box-Jenkins

Manuscript received 30 January, 2018; accepted 23 August, 2018. problems. Another study which is about fractional system modelling of the CARMA (controlled autoregressive moving average) systems using LMS algorithms is presented by Chaudhary and Raja [8]. In the other study, the model parameters of time delay systems are estimated using the ABC algorithm [9]. On the other hand, new Luus-Jaakol (NLJ) algorithm is used for the identification of non-integer systems by Ming and Dazi [10].

Fractional calculus has been quite popular research area in study of engineering in last two decades although it has been known about 300 years. Beginning of the non-integer calculus goes to the correspondence between Leibniz and L'Hôpital in 1965 [11]. The first study on the fractional order proportional-integral-derivative (FOPID) controller was given by Podlubny et al. [12], [13] in the literature. Unlike the classical PID, two additional parameters which are called $\lambda, \mu$ are proposed by Podlubny for the fractional PID. Researchers have stated that these two parameters strengthen the hand of the users in terms of some properties such as flexibility and stability. The works about fractional controllers has increased day by day [14]-[25]. A novel design method of a FOPID for fractional order with time delay systems is given by Boudjehem [14]. In other studies, the FOPID controllers has been suggested for fractional order unstable time delay systems [15], [16]. Moreover, stability analysis was also carried out in these studies. An investigation about the parameter estimation of $\mathrm{PI}^{\lambda} \mathrm{D}^{\mu}$ controller via the DE algorithm has been presented by Martin et al. [17]. A robust FOPID controller has been suggested for wind turbine generators by Ghasemi et al. [18]. Fractional order controller design based on the particle swarm optimization (PSO) method has been proposed by Cao et al. [19]. The design of a PID controller for noninteger processes with time delay is debated by Ozbay et al. [20]. A novel procedure for analog implementation of the fractional-order controller using the Inverse-Follow-theLeader Feedback topology is given by Dimeas et al. [21]. Different tuning methods such as Ziegler-Nichols modified method, PSO, neural network have been also used in designing a FOPID controller by researchers [22]-[24]. In another study, the design of fractional order PID controller has been proposed for higher order processes by Shah and Agashe [25]. On the other hand, in the study presented by Senberber and Bagis [26], a detailed discussion on the performance of FOPID controllers designed by $\mathrm{ABC}$ 
algorithm for fractional order systems.

This study consists of two basic stages; system modelling and fractional order PID controller design. For this purpose, the modelling operation based on the use of two model structures is performed for two different integer order systems given in the literature. Obtained model structures are used in fractional order controller design. Model parameters are obtained by using $\mathrm{ABC}$ and $\mathrm{DE}$ algorithms. However, the Nelder-Mead algorithm based Simulink program is also used to achieve the optimum controller parameters. In determining the parameters of the integer and fractional order models, in accordance with literature, ISE performance criterion is used by the algorithms. On the other hand, the controller parameters are obtained by using four different cost functions namely ISE, ITSE, IAE and ITAE. At this stage, the Matlab/Simulink program package is used to examine the controller performance. Thus, the performances of the models, algorithms and model based controllers are comparatively investigated. This purpose constitutes the basic motivation of this work.

\section{AlgORITHMS USED IN THE STUDY}

\section{A. Artificial Bee Colony Algorithm (ABC)}

The ABC algorithm was presented to the literature by Karaboğa in 2005 [26]-[30]. The algorithm simulates the foraging behaviour of honey bees and it uses for optimizing numerical problems. The algorithm consists of three basic components: employed bees, onlooker bees and scout bees. Employed bees are initialized randomly. The basic principle of the $\mathrm{ABC}$ is finding $\mathrm{N}$ solutions with $\mathrm{D}$ parameters via employed bees. When onlooker bees cannot find better solutions, the employed bee turns into a scout bee in order to find better solutions in another food source. The possibility of choosing a source in 'position i' is as follows

$$
p_{i}=f\left(\beta_{i}\right) / \sum_{n=1}^{F S} f\left(\beta_{n}\right)
$$

where $p_{i}$ is possibility of food source, $f\left(\beta_{i}\right)$ represents the fitness value of $\beta_{i}^{\text {th }}$ solution and $F S$ is the number of food sources. After the onlooker bees have observed the dance of the employed bees and selected the source of $\beta_{i}$ by the probability value in (2), they identify a source in the neighborhood of this source and begin to take the nectar of the source. That is, it makes a comparison between the sources around $\beta_{i}$. The position information of the selected neighbors is calculated as follows

$$
\beta_{i}(\mathrm{x}+1)=\beta_{i}(\mathrm{x}) \pm \phi_{i}(\mathrm{x})
$$

where $\phi_{i}(x)$ is the randomly generated step size used to find a source with more nectar around $\beta_{i}$. If the amount of nectar belonging to $\beta_{i}(\mathrm{x}+1)$ is greater than number of nectars from the source in $\beta_{i}(\mathrm{x})$, then the bee goes the hive to share this knowledge with the others and keeps $\beta_{i}(\mathrm{x}+1)$ as a new position, otherwise $\beta_{i}(\mathrm{x})$ is stored in memory. If the number of nectar amount in the $\beta_{i}$ position can not be improved by the number of the "limit" parameters, the source of $\beta_{i}$ is abandoned. The scout bees become the employed bees, randomly explore and assign to the new source $\beta_{i}$.

\section{B. Differential Evolution Algorithm (DEA)}

DEA is a population-based heuristic optimization technique developed by Price and Storn in 1995, which is based on genetic algorithms in terms of operations and operators [31], [32]. Although the DEA has fewer parameters, it is able to provide effective results especially for continuous data. The crossover, mutation and selection operators in the genetic algorithm are also used in DEA. Unlike the genetic algorithm, each operator is not applied to the entire population in order. Chromosomes are handled one by one using a random selection of three other chromosomes to obtain a new individual. During these operations, mutation and crossover operators are used. The current chromosome and the obtained new chromosome are compared, and the best individual is transferred to the next population. The selection operator is involved in optimization at this stage.

On the other hand, the mutation operator makes randomly changes quantities on some genes of the current chromosome. As a result of these changes, the solution point represented by the chromosome is moved in the solution space. The equation of the mutation operator is given below.

$$
\mathrm{V}_{\mathrm{i}}^{(\mathrm{G}+1)}=\mathrm{X}_{\mathrm{a}}^{(\mathrm{G})}+\mathrm{F}\left(\mathrm{X}_{\mathrm{b}}^{(\mathrm{G})}-\mathrm{X}_{\mathrm{c}}^{(\mathrm{G})}\right),
$$

where $V$ is the mutation vector, $X_{a}, X_{b}, X_{c}$ are randomly chosen different possible solutions, $F$ is the scaling factor and $G$ is the generation.

With the selection operator, a new generation is created by evaluating the current generation and the new chromosomes produced. The possibilities of chromosomes in the new generation depend on their fitness or qualities. Chromosomes which have higher solution quality from the other chromosomes are assigned as individuals of the new generation in the end of the comparison.

\section{SyStem MODELling AND CONTROLlER DESIGN}

\section{A. Definition of the Modelling Problem}

Choosing the right model has a key importance in order to obtain the characteristic specifications of the process to be controlled. On the other hand, it is also necessary to obtain the parameters of the determined model quickly and correctly. The main purpose of the system modelling is to have the characteristic features of the process defined by an appropriate model with the minimum error value. Especially, if the systems are oscillatory, with time-delayed or over-parameterized, this modelling operation can be even more difficult. Therefore, the performance of the algorithms used is critically important for the success of the modelling.

In this study, two model structures have been considered for the modelling process. While (4) belongs to the integer order model (Gm1), (5) defines a fractional order model (Gm2). Thus, five parameters $\left(a_{0}, a_{l}, a_{2}, b_{0}\right.$ and $\left.L\right)$ for the (4) and seven parameters $\left(a_{0}, a_{1}, a_{2}, b_{0}, L, k_{1}\right.$ and $\left.k_{2}\right)$ for the (5) are optimized. In the modelling process for two systems $\left(\mathrm{G}_{1}\right.$ [33] and $\mathrm{G}_{2}$ [34]) from the literature, the model parameters have been determined by using $\mathrm{DE}$ and $\mathrm{ABC}$ algorithms. These are given in (6) and (7). While the time delay for the 
system given as $\mathrm{G}_{2}$ in (6) is defined as $2 \mathrm{sec}$ in the literature, it is used as $0.5 \mathrm{sec}$ in this study. The ISE was taken into consideration as performance criteria:

$$
\begin{gathered}
G m 1=\frac{b_{0}}{a_{2} s^{2}+a_{1} s+a_{0}} \exp (-\mathrm{Ls}), \\
G m 2=\frac{b_{0}}{a_{2} s^{k_{2}}+a_{1} s^{k_{1}}+a_{0}} \exp (-\mathrm{Ls}), \\
G_{1}(\mathrm{~s})=\frac{1}{(s+1)\left(\mathrm{s}^{2}+0.2 s+0.1\right)} \\
G_{2}(\mathrm{~s})=\frac{9}{\mathrm{~s}^{2}+1.2 s+9} e^{-0.5 s} .
\end{gathered}
$$

\section{B. Controller Design Problem}

The basic controller structure is shown in Fig. 1, where $\mathrm{C}(\mathrm{s})$ is the controller to be designed according to $\mathrm{G}(\mathrm{s})$.

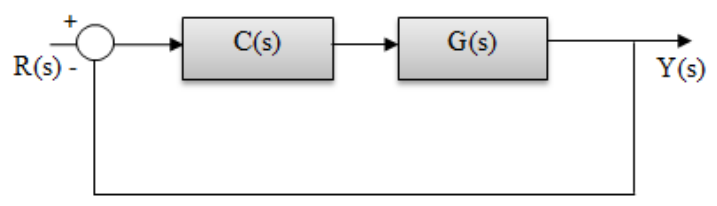

Fig. 1. Block diagram of a basic control system.

In this stage of the study, the G(s) structure consists of new processes obtained as a result of the modelling operation. The $\mathrm{C}(\mathrm{s})$ structure that represents the controller element is composed of fractional PID. In (8), the basic structure of the fractional PID controller $\mathrm{G}_{\text {fopid }}(S)$ is given

$$
G_{f o p i d}(\mathrm{~s})=\mathrm{Kp}+\frac{K i}{s^{\lambda}}+K d . s^{\mu}=K p+K i . s^{-\lambda}+K d . s^{\mu}
$$

FOPID controller consists of two additional parameters called as $\lambda$ and $\mu$ that define integration and differentiation orders unlike the classical PID. These two parameters provide flexibility and durability for the controller. In order to examine the performance of the controller, four different objective functions are used: ISE, ITSE, IAE and ITAE. Thus, the objective functions used in this stage of the study are given in (9)-(12):

$$
\begin{aligned}
I S E & =\int_{0}^{\infty} e^{2}(\mathrm{t}) \mathrm{dt}, \\
I T S E & =\int_{0}^{\infty} \mathrm{t} \cdot e^{2}(\mathrm{t}) \mathrm{dt}, \\
I A E & =\int_{0}^{\infty}|e(\mathrm{t})| \mathrm{dt}, \\
I T A E & =\int_{0}^{\infty} t|e(\mathrm{t})| \mathrm{dt} .
\end{aligned}
$$

In this part of the study, the Matlab/Simulink program [35] package was used in the controller design for each obtained new process. The studies done for each of the processes and performance indicators were run 30 times separately, and the best results were considered for each performance indexes. The error values and FOPID controller parameters obtained by the algorithms are reported in tables.

\section{Simulation Results}

This section in the study consists of two parts. The first part is related to the modelling works and the second part is about the controller design for the new processes obtained by modelling process. The results obtained in both stages are shown in table form with parameter results, and the responses of the closed-loop transfer functions are shown in figures.

For the modelling phase, two higher order and oscillatory processes in the literature are considered, and parameter estimation is made by using $\mathrm{ABC}$ and $\mathrm{DE}$ algorithms. These systems have been preferred in order to compare the modelling performance of the algorithms. For an objective comparison, the control parameters of the algorithms were taken into the same values. The number of iterations is 100 , the colony (or population) size is 10 , and the parameter search interval is selected as [0-100]. While scaling factor (F) 0.8 , crossover rate is selected as 0.9 for the DEA, the limit value is defined according to the expression of [(colonies size $\mathrm{x}$ number of parameter)/2] for $\mathrm{ABC}$ algorithm. The Gmi and $\mathrm{Gmf}$ terms in the figures represent the integer and fractional models given in (4) and (5), respectively.

The values of the model parameters proposed for different processes are given in Table I. While five parameters were estimated for Gm1 (integer) model, seven parameters were obtained for $\mathrm{Gm} 2$ (fractional) model. The performance criterion used in the modelling section is only the ISE error. The modelling operation for the processes of $\mathrm{G}_{1}$ and $\mathrm{G}_{2}$ was performed in the range of [0-50] sec and [0-15] sec, respectively. The obtained results clearly show that fractional order models have better results according to integer models in the processes. The successful performance of the fractional model is particularly evident in the third process. Although the both algorithms have exhibited almost the same performance for integer models, the ABC algorithm presents the better results in fractional models except for the first process.

Figure 2 shows the step responses and iteration-error variation curves obtained in the modelling operations for all processes. It can be seen from Fig. 2(a) and Fig. 2(b) that the $\mathrm{Gmf}(\mathrm{Gm} 2)$ model has more successful result than the Gmi (Gm1) model. The actual and Gmf model outputs for the process $G_{1}$ are almost identical to each other. However, for the Gmi process, the differences in the peak points of the step response are particularly striking. In Fig. 2(c), which shows the iteration-error variation graph during the modelling, the convergence rates of the algorithms are shown. From graphical representation, ABC algorithm is more successful than DE algorithm for both models. Figure 2(d), Fig. 2(e) and Fig. 2(f) show the modelling graphs of the time delay system specified as $\mathrm{G}_{2}$. The result obtained in the $G_{2}$ process is quite similar to the $G_{1}$ process. But the convergence speeds of the algorithms are fairly close for both models. 


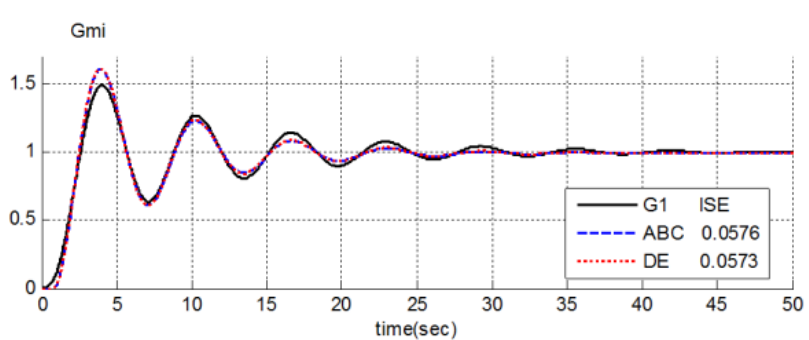

(a)

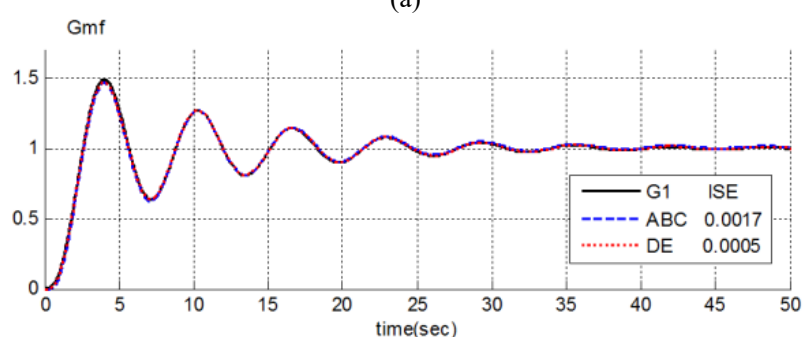

(b)

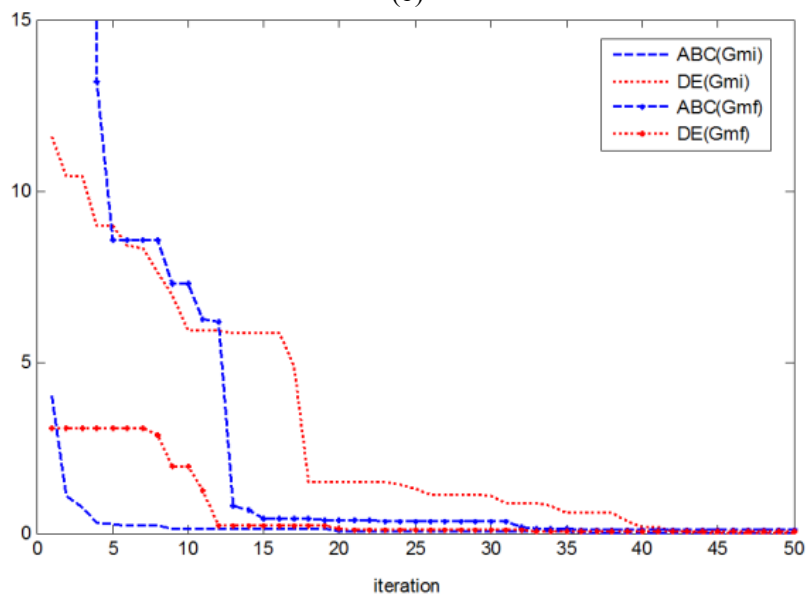

(c)

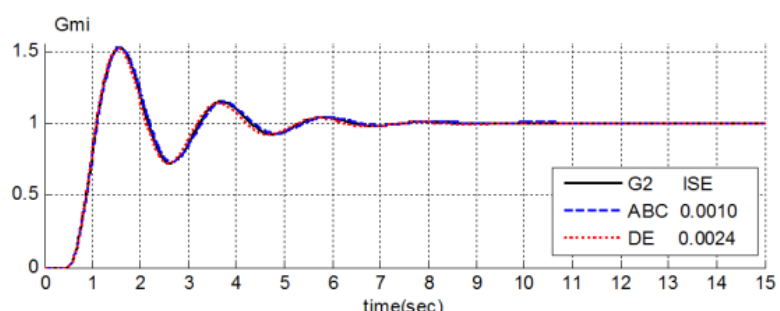

(d)

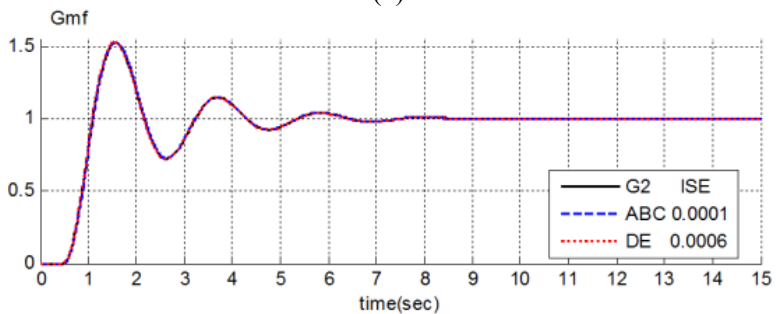

(e)

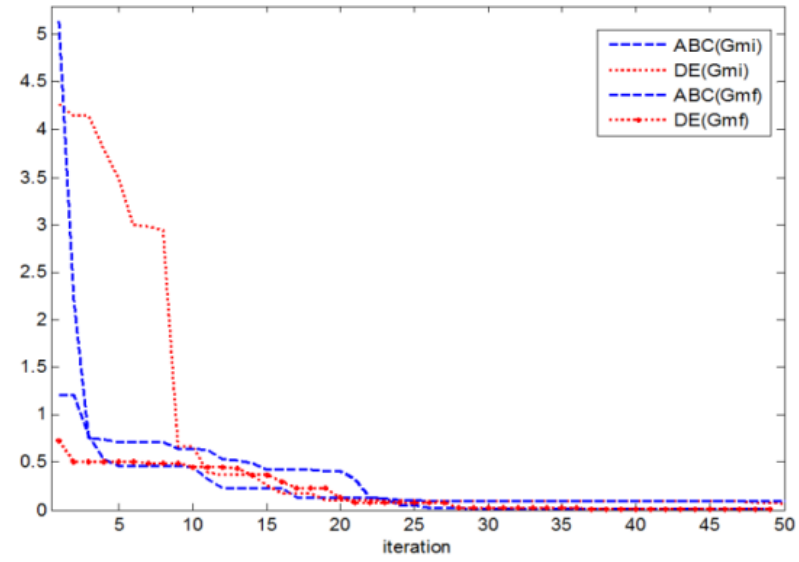

(f)

Fig. 2. For $\mathrm{G}_{1}\left((\mathrm{a})\right.$, (b)) and $\mathrm{G}_{2}((\mathrm{~d})$, (e)), step responses ((a), (b), (d), and (e) and error-reduction curves ((c), (f)) obtained in the modelling.

TABLE I. MODEL PARAMETERS OBTAINED USING ABC AND DE ALGORITHM.

\begin{tabular}{|c|c|c|c|c|c|c|c|c|c|c|}
\hline Proc. & Model & Algr. & $\mathbf{b}_{0}$ & $\mathbf{a}_{2}$ & $a_{1}$ & $\mathbf{a}_{0}$ & $\mathbf{L}$ & $\mathbf{k}_{2}$ & $\mathbf{k}_{1}$ & ISE \\
\hline \multirow{4}{*}{$\mathbf{G}_{1}$} & \multirow{2}{*}{ Gmi } & DE & 67.04 & 67.48 & 20.05 & 67.51 & 0.757 & - & - & 0.0573 \\
\hline & & $\mathrm{ABC}$ & 60.49 & 61.17 & 18.34 & 60.98 & 0.757 & - & - & 0.0576 \\
\hline & \multirow{2}{*}{ Gmf } & $\mathrm{DE}$ & 19.413 & 26.555 & 23.195 & 19.506 & 0.2242 & 2.500 & 1.0977 & 0.0005 \\
\hline & & $\mathrm{ABC}$ & 43.519 & 61.725 & 50.753 & 43.527 & 0.2095 & 2.4869 & 1.0492 & 0.0017 \\
\hline \multirow{4}{*}{$\mathbf{G}_{2}$} & \multirow{2}{*}{ Gmi } & 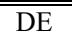 & 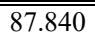 & \begin{tabular}{c|}
9.386 \\
\end{tabular} & $\begin{array}{l}11.560 \\
\end{array}$ & $\begin{array}{l}88.261 \\
\end{array}$ & $\begin{array}{l}0.510 \\
\end{array}$ & - & - & $\overline{0.0024}$ \\
\hline & & $\mathrm{ABC}$ & 90.601 & 10.299 & 12.441 & 90.380 & 0.501 & - & - & 0.0010 \\
\hline & \multirow{2}{*}{$\mathrm{Gmf}$} & $\mathrm{DE}$ & 81.345 & 9.9972 & 7.7785 & 81.263 & 0.5183 & 1.929 & 0.9024 & 0.0006 \\
\hline & & $\mathrm{ABC}$ & 96.778 & 9.7217 & 12.291 & 96.937 & 0.5081 & 2.031 & 1.0867 & 0.0001 \\
\hline
\end{tabular}

TABLE II. PARAMETER VALUES OF FOPID CONTROLLERS DESIGNED FOR GMF PROCESSES.

\begin{tabular}{|c|c|c|c|c|c|c|c|c|}
\hline Pro. & Algr. & $\begin{array}{l}\text { Perform. } \\
\text { index }\end{array}$ & Кр & $\mathbf{K i}$ & Kd & $\lambda$ & $\mu$ & $\begin{array}{l}\text { Error } \\
\text { Value }\end{array}$ \\
\hline \multirow{6}{*}{$\mathbf{G}_{1}$} & \multirow{3}{*}{$\mathrm{ABC}$} & ISE & 3.8501 & 2.9101 & 4.5779 & 1.0022 & 1.500 & 0.3451 \\
\hline & & ITSE & 2.8663 & 3.1407 & 4.3803 & 0.9002 & 1.4362 & 0.0888 \\
\hline & & ITAE & 3.6784 & 3.4021 & 4.7923 & 0.9973 & 1.4332 & 0.3925 \\
\hline & \multirow{3}{*}{$\mathrm{DE}$} & ISE & 3.4662 & 2.7697 & 4.2347 & 0.9697 & 1.500 & 0.3770 \\
\hline & & ITSE & 1.3832 & 2.6944 & 3.2059 & 0.8315 & 1.3020 & 0.1818 \\
\hline & & ITAE & 4.5558 & 2.5582 & 3.9845 & 0.9993 & 1.4593 & 0.3492 \\
\hline \multirow{7}{*}{$\mathbf{G}_{2}$} & \multirow{4}{*}{$\mathrm{ABC}$} & ISE & 0.6575 & 1.4069 & 0.1725 & 0.9038 & 1.4435 & 0.5888 \\
\hline & & ITSE & 0.7667 & 1.3663 & 0.1470 & 1.0568 & 1.4946 & 0.1889 \\
\hline & & IAE & 0.5797 & 1.3054 & 0.1359 & 1.0340 & 1.4064 & 0.8048 \\
\hline & & ITAE & 0.4382 & 1.2591 & 0.1284 & 1.0087 & 1.3050 & 0.4393 \\
\hline & \multirow{3}{*}{$\mathrm{DE}$} & ISE & 0.6623 & 1.4979 & 0.1600 & 0.9898 & 1.4196 & 0.5963 \\
\hline & & ITSE & 0.6811 & 1.4591 & 0.1489 & 1.0500 & 1.4254 & 0.1882 \\
\hline & & ITAE & 0.4297 & 1.2842 & 0.1300 & 1.0192 & 1.2906 & 0.4028 \\
\hline
\end{tabular}


TABLE III. PARAMETER VALUES OF FOPID CONTROLLERS DESIGNED FOR GMI MODELS.

\begin{tabular}{|c|c|c|c|c|c|c|c|c|}
\hline Pro. & Algr. & $\begin{array}{l}\text { Perform. } \\
\text { Index }\end{array}$ & Kр & $\mathbf{K i}$ & Kd & $\lambda$ & $\mu$ & $\begin{array}{l}\text { Error } \\
\text { Value }\end{array}$ \\
\hline \multirow{6}{*}{$\mathbf{G}_{1}$} & \multirow{3}{*}{$\mathrm{ABC}$} & ISE & 1.3334 & 0.7312 & 1.0963 & 1.1666 & 1.4994 & 0.9261 \\
\hline & & ITSE & 0.9531 & 0.7797 & 1.0379 & 1.0424 & 1.3881 & 0.5209 \\
\hline & & ITAE & 0.4663 & 0.7630 & 0.8303 & 0.9999 & 1.1654 & 1.3717 \\
\hline & \multirow{3}{*}{$\mathrm{DE}$} & ISE & 0.9168 & 1.3117 & 1.2810 & 0.7772 & 1.3857 & 0.9869 \\
\hline & & ITSE & 1.1186 & 0.8540 & 1.0816 & 1.1297 & 1.3898 & 0.6741 \\
\hline & & ITAE & 0.2058 & 0.8437 & 0.8353 & 0.9996 & 0.9794 & 1.9412 \\
\hline \multirow{7}{*}{$\mathbf{G}_{2}$} & \multirow{4}{*}{$\mathrm{ABC}$} & ISE & 0.8485 & 1.4591 & 0.1659 & 1.0558 & 1.4999 & 0.5854 \\
\hline & & ITSE & 0.8181 & 1.3900 & 0.1577 & 1.0611 & 1.4912 & 0.1870 \\
\hline & & IAE & 0.5918 & 1.3152 & 0.1460 & 1.0222 & 1.3937 & 0.8008 \\
\hline & & ITAE & 0.4639 & 1.2734 & 0.1360 & 1.0202 & 1.3023 & 0.4174 \\
\hline & \multirow{3}{*}{$\mathrm{DE}$} & ISE & 0.8318 & 1.4886 & 0.1560 & 1.0578 & 1.500 & 0.5852 \\
\hline & & ITSE & 0.7997 & 1.3877 & 0.1459 & 1.0637 & 1.4994 & 0.1857 \\
\hline & & ITAE & 0.4073 & 1.2245 & 0.1228 & 1.0019 & 1.2812 & 0.4497 \\
\hline
\end{tabular}

The parameter values of FOPID controllers designed for new Gmf and Gmi models obtained from the modelling operation are given in Table II and Table III. As previously mentioned, four different error indices (ISE, ITSE, IAE and ITAE) were used for benchmarks of the FOPID controller. On the other hand, for the processes of $G_{1}$ and $G_{2}$, step responses of new $\mathrm{Gmf}$ and $\mathrm{Gmi}$ models under control are presented in Fig. 3 and Fig. 4.
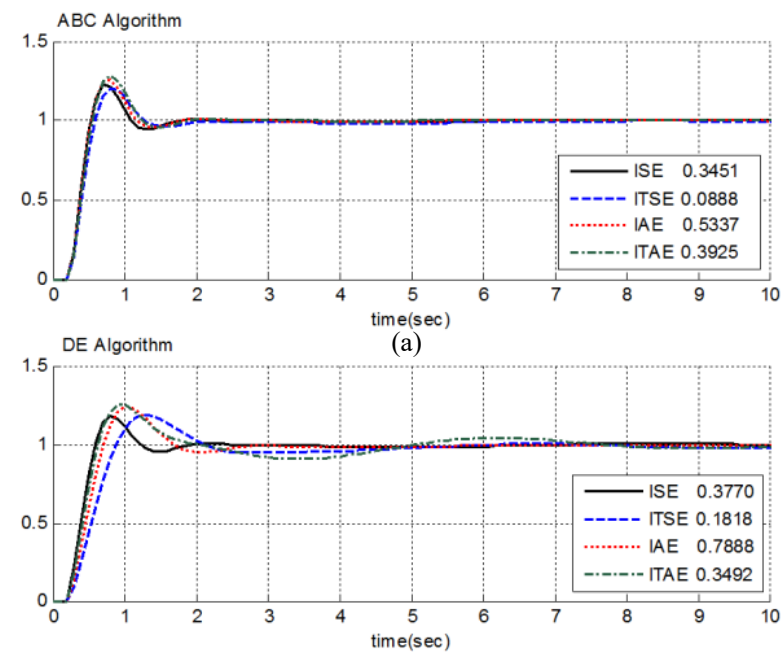

(b)
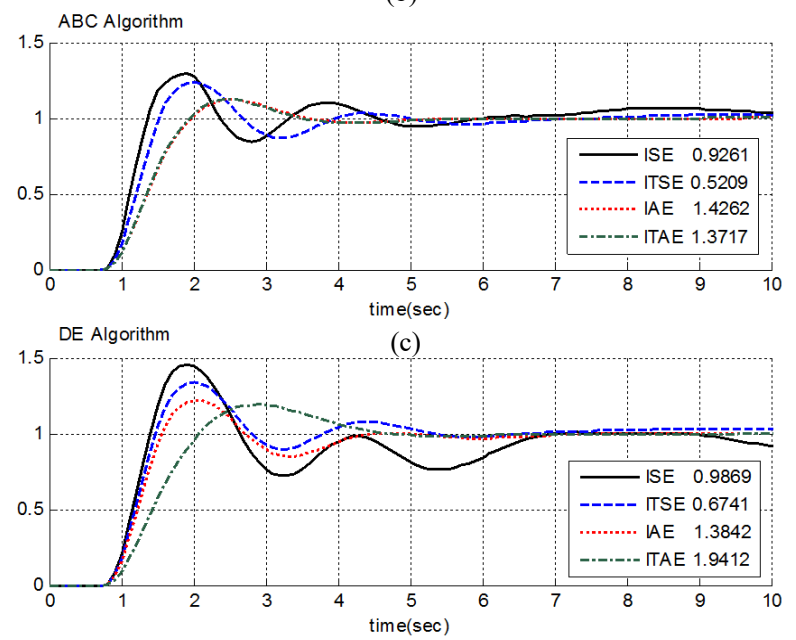

(d)

Fig. 3. For $\mathrm{G}_{1}$ process, step responses of new $\mathrm{Gmf}((\mathrm{a}),(\mathrm{b}))$ and $\mathrm{Gmi}((\mathrm{c})$, (d)) models under control.
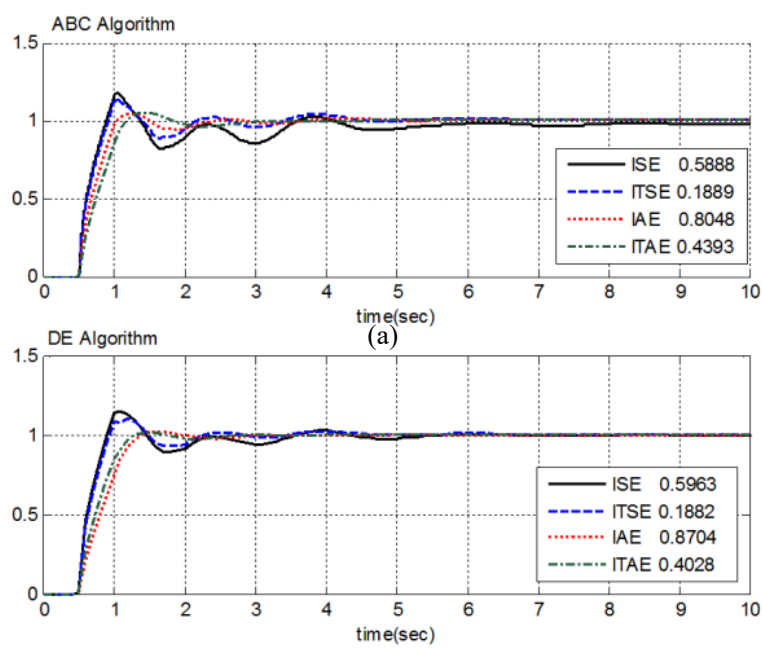

(b)
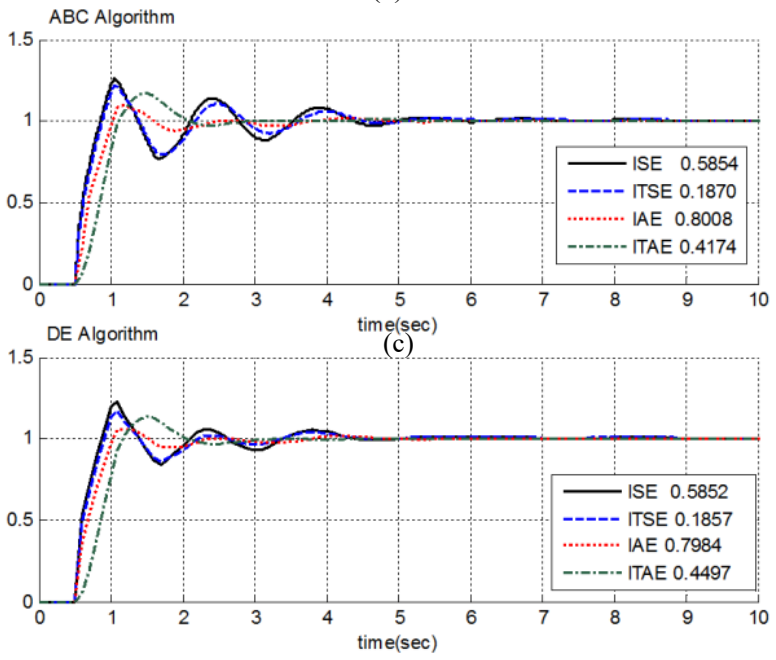

(d)

Fig. 4. For $\mathrm{G}_{2}$ process, step responses of new $\mathrm{Gmf}((\mathrm{a})$, (b)), and $\mathrm{Gmi}((\mathrm{c})$, (d)) models under control.

\section{DISCUSSION}

From the results in the tables, the controllers designed for the $\mathrm{ABC}$ based $\mathrm{Gmi}$ and $\mathrm{Gmf}$ models in the $\mathrm{G}_{1}$ process have the lowest error values for all performance criteria except ITAE. For $\mathrm{G}_{1}$ process, the superiority of the ABC algorithm according to the DE algorithm is evident from Table III and Fig. 3. Also, the controller design for the fractional model 
Gmf for both algorithms provided more successful results than the controller design for the classical model. Especially when the some important characteristics such as overshoot, rise time and settling time are taken into account, the difference between the performances of the model-based controllers can be clearly seen from Fig. 3(a)-Fig. 3(d).

Unlike the $G_{1}$ process, the results in the $G_{2}$ process are very close together. There are no obvious differences between the algorithms or the obtained new models. From Fig. 3 and Fig. 4, it can be said that the controllers designed for Gmf structures have a lower overshoot values than the controllers designed for Gmi structures. According to Fig. 3 and Fig. 4, it can be seen that the controller designed for the $\mathrm{ABC}$ algorithm based model responds more quickly than the $\mathrm{DE}$ based other one. With a careful observation of these figures, it can be noticed that the ABC based FOPID controller provides the lower error values than the $\mathrm{DE}$ based FOPID controller.

\section{CONCLUSIONS}

In this work, integer and fractional order models are proposed firstly for oscillatory and high order systems in the literature. Parameter estimations of these models were made by using $\mathrm{ABC}$ and $\mathrm{DE}$ algorithms. And subsequently, FOPID controller designs have been implemented for these models based new systems that reflect the characteristics of the processes. As a result of the study it is possible to say the following:

The fractional order model structures proposed for highorder and oscillatory systems that are relatively difficult to identify by a model, have achieved successful results. It can be said that the performance of the integer order model structures is also satisfactory. When examining the modelling study, it is clear that the fractional models have a better ability to describe the systems than the integer models. Considered the modelling process, the ABC algorithm has been produced better solutions nearly for the processes. In particular, the performance of the $\mathrm{ABC}$ algorithm for the fractional model structures should be noticed. As can be seen from the iteration-error variation curves, it can be said that the ABC algorithm converges much faster to the minimum error value. It can be stated that the structures of the FOPID controller designed for both model structures achieved successful results. However, it is clearly obvious that the closed loop responses of the systems having fractional model based FOPID controllers are more desirable than the other systems using integer models. The performance of $\mathrm{ABC}$ and $\mathrm{DE}$ based models in controller design is not far from each other. Nevertheless, the results tell us that the performance of the controller depend on $\mathrm{ABC}$ model is slightly better than the other algorithm.

As a result of this study, if difficult or complex systems are defined based on a fractional model and are also controlled using a fractional PID controller, it is possible to obtain effective results that are appropriate for the desired control purposes. Furthermore, using the ABC algorithm, model and/or controller performance can be significantly improved and much more impressive results can be achieved in the control system.

\section{REFERENCES}

[1] L. Ljung, System Identification: Theory for the User. Prentice Hall, 1987.

[2] T. Soderstrom, P. Stoica, System Identification. Prentice Hall, 1989.

[3] H. Zorlu, S. Ozer, "Identification of nonlinear systems by using clonal selection algorithm", IEEE 17t Signal Processing and Communications Applications Conf. (SIU 2009), Antalya, Turkey, 2009. (in Turkish).

[4] A. Bagis, H. Senberber, "Modeling of higher order systems using artificial bee colony algorithm", An International Journal of optimization and Control: Theories \& Applications, vol. 6, no. 2, pp. 129-139, 2016. DOI: 10.11121/ijocta.01.2016.00298.

[5] S. Mete, H. Zorlu, S. Ozer, "System identification using Hammerstein model optimized with differential evolution algorithm", $A E U$ International Journal of Electronics and Communications, vol. 70, no. 12 , pp. $1667-1675$, 2016. DOI: $10.1016 /$ j.aeue.2016.10.005.

[6] X. Deng, "System identification based on particle swarm optimization algorithm", Int. Conf. on Computational Intelligence and Security (CIS 2009), pp. 259-263, 2009. DOI: 10.1109/CIS.2009.167.

[7] N. I. Chaudhary, M. A. Z. Raja, "Design of fractional adaptive strategy for input nonlinear Box-Jenkins systems", Signal Process, vol. 116, pp. 141-151, 2015. DOI: 10.1016/j.sigpro.2015.04.015.

[8] M. A. Z. Raja, N. I. Chaudhary, "Two-stage fractional least mean square identification algorithm for parameter estimation of CARMA systems", Signal Process, vol. 107, pp. 327-339, 2015. DOI: 10.1016/j.sigpro.2014.06.015.

[9] H. Senberber, A Bagis, "Performance investigation of artificial bee colony algorithm in modeling of systems with delay", Symposium on Innovations in Intelligent Systems and Applications (ASYU 2012), Trabzon, Turkey, pp. 164-168, 2012. (in Turkish).

[10] M. Zhang, D. Li, "Fractional system identification based on improved NLJ algorithm", 24th Chinese Control and Decision Conf. (CCDC 2012), 2012, pp. 1057-1061. DOI: 10.1109/CCDC.2012.6244167.

[11] J. T. Machado, A. M. Galhano, J. J. Trujillo, "On development of fractional calculus during the last fifty years", Scientometrics, vol. 98, no. 1, pp. 577-582, 2014. DOI: $10.1007 /$ s11192-013-1032-6.

[12] I. Podlubny, L. Dorcak, I. Kostial, "On fractional derivatives, fractional-order dynamic systems and $\mathrm{PI}^{\lambda} \mathrm{D}^{\mu}$ controllers", in Proc. 36th Conf. Decision \& Control, pp. 4985-4990, 1997.

[13] I. Podlubny, "Fractional-order systems and $\mathrm{PI}^{\lambda} \mathrm{D}^{\mu}$ controllers", IEEE Trans. Automatic Control, vol. 44, no. 1, pp. 208-214, 1999. DOI: $10.1109 / 9.739144$

[14] B. Boudjehem, D. Boudjehem, "Fractional order controller design for desired response", in Proc. Inst Mech Eng, Part 1: J Syst Control Eng, vol. 227, no. 2, pp. 243-251, 2013. DOI: $10.1177 / 0959651812456647$

[15] I. Kheirizad, K. Khandani, A. A. Jalali, "Stabilisability analysis of high-order unstable processes by fractional-order controllers", Int. Journal of Control, vol. 86, no. 2, pp. 244-252, 2013. DOI: 10.1080/00207179.2012.723138.

[16] I. Kheirizad, K. Khandani, A. A. Jalali, "Stabilization of fractionalorder unstable delay systems by fractional-order controllers", Journal of System and Control Engineering, vol. 226, no. 9, pp. 1166-1173, 2012. DOI: $10.1177 / 0959651812453668$.

[17] F. Martin, C. A. Monje, L. Moreno, C. Balaguer, "DE-based tuning of $\mathrm{PI}^{\lambda} \mathrm{D}^{\mu}$ controllers", ISA Trans., vol. 59, pp. 398-407, 2015. DOI: 10.1016/j.isatra.2015.10.002

[18] S. Ghasemi, A. Tabesh, J. Askari-Marnani, "Application of fractional calculus theory to robust controller design for wind turbine generators", IEEE Trans. Energy Convers, vol. 29, pp. 780-787, 2014. DOI: 10.1109/TEC.2014.2321792.

[19] J. Y. Cao, B. G. Cao, "Design of fractional order controller based on particle swarm optimization", International Journal of Control, Automation and Systems, vol. 4, pp. 775-781, 2006.

[20] H. Ozbay, C. Bonnet, A. R. Fioravanti, "PID controller design for fractional-order systems with time delays", System Control Letts, vol. 61, pp. 18-23, 2012. DOI: 10.1016/j.sysconle.2011.09.011.

[21] I. Dimeas, I. Petras, C. Psychalinos, "New analog implementation technique for fractional-order controller: a DC motor control", $A E U-$ International Journal Electron Communication, vol. 78, pp. 192-200, 2017. DOI: 10.1016/j.aeue.2017.03.010.

[22] H. Li, Y. Luo, Y. Q. Chen, "A fractional order proportional and derivative (FOPD) motion controller: tuning rule and experiments", IEEE Trans. Control Systems Technology, vol. 18, no. 2, pp. 516-520, 2010. DOI: 10.1109/ TCST.2009.2019120.

[23] Y. Luo, Y. Q. Chen, C. Y. Wang, Y. G. Pi, "Tuning fractional order proportional integral controllers for fractional order systems", Journal 
of Process Control, vol. 20, no. 7, pp. 823-831, 2010. DOI: 10.1016/j.jprocont.2010.04.011.

[24] F. Padula, A. Visioli, "Tuning rules for optimal PID and fractionalorder PID controllers", Journal of Proc. Cont., vol. 21, no. 1, pp. 6981, 2011. DOI: $10.1016 / j$ jpprocont. 2010.10.006.

[25] P. Shah, S. Agashe, "Design and optimization of fractional PID controller for higher order control system", Int. Conf. IEEE ICART, pp. 588-592, 2013.

[26] H. Senberber, A. Bagis, "Fractional PID controller design for fractional order systems using $\mathrm{ABC}$ algorithm", in IEEE Proc. of $21^{s t}$ International Conference Electronics, Palanga, Lithuania, 2017, pp. 1-7. DOI: 10.1109/ELECTRONICS.2017.7995218.

[27] H. Senberber, "Artificial bee colony algorithm performance investigation of system modeling", M.Sc. Thesis, Erciyes University, Graduate School of Natural and Applied Sciences, Kayseri, Turkey, 2012. (in Turkish).

[28] D. Karaboga, C. Ozturk, "A novel clustering approach: artificial bee colony (ABC) algorithm", Applied Mathematics and Computation, vol. 11, pp. 652-657, 2011. DOI: 10.1016/j.asoc.2009.12.025.

[29] D. Karaboga, B. Akay, "A comparative study of artificial bee colony algorithm", Applied Math. and Comp., vol. 214, pp. 108-132, 2009.
DOI: 10.1016/j.amc.2009.03.090.

[30] H. Senberber, A. Bagis, "Fractional order PID controller design for higher order systems using artificial bee colony algorithm", TOK17, Istanbul, Turkey, pp. 201-205, 2017. (in Turkish).

[31] R. Storn, "System design by constraint adaptation and differential evolution", IEEE Trans.on Evolut. Comp., vol. 3, no. 1, pp. 22-34, 1999. DOI: $10.1109 / 4235.752918$.

[32] R. Storn, K. Price, "Differential evolution-a simple and efficient heuristic for global optimization over continuous spaces", Journal of Global Optimization, vol. 11, pp. 341-359, 1997. DOI: 10.1023/A:1008202821328.

[33] D. Puangdownreong, S. Sujitjorn, "S. Obtanining an optimum PID controller via adaptive tabu search", ICANNGA, LNCS, vol. 4432, Warsaw, Poland, 2007, pp. 747-755. DOI: 10.1007/978-3-540-716297_84.

[34] S. Srivastava, A. Misra, S. K. Thakur, V. S. Pandit, "An optimal PID controller via LQR for standard second order plus time delay systems", ISA Trans., vol. 60, pp. 244-253, 2016. DOI: 10.1016/j.isatra.2015.11.020

[35] MathWorks, Matlab\&Simulink Getting Started Guide. R2014a. The MathWorks, Inc., 2014. 